\title{
Chapter 53 \\ Concluding Reflections and Presentation of an EBOCD Conceptual Process Model
}

\author{
Robert G. Hamlin \\ University of Wolverhampton, UK \\ Jenni Jones \\ University of Wolverhampton, $U K$ \\ Andrea D. Ellinger \\ The University of Texas at Tyler, USA
}

\begin{abstract}
This chapter begins by presenting a synopsis of insights on EBOCD practice gleaned from the Section 2 chapters, and a range of extant and emergent generalized (common) insights and lessons about evidencebased initiatives for OCD that have resulted from a multiple cross-case comparative analysis of the 33 reflective case histories presented in Section 3. It then offers a response to the skepticisms expressed by McLean and Kim, the authors of Chapter 52, about the reality of EBOCD ever existing beyond what they suggest could be outlier case history examples of $O C D$ by drawing attention to the wide range of extant best evidence that informed them. The chapter concludes with an EBOCD Conceptual Process Model which offers a pathway forward for bridging the reputed research-practice gap in the field of OCD and $H R D$, and for generating new bodies of best evidence and practice-to-theory research opportunities.
\end{abstract}

\section{INTRODUCTION}

We have four aims in writing this concluding chapter. The first is to provide a synopsis of insights that we have gleaned from the nine Section 2 chapters. The second aim is to present the results of our multiple cross-case comparative analysis (MCCCA) of the 33 'reflective case histories' described by the authors of the Section 3 chapters. This analysis validates 10 generalized (common) 'insights' and 'lessons' about OCD and EBOCD practice identified by Hamlin (2001) over 18 years ago. It also reveals 10

DOI: $10.4018 / 978-1-5225-6155-2 . c h 053$ 
other emergent common 'insights' and 'lessons' to be gained and learned from the various illustrations of 'critically reflective', 'research-informed' and 'evidence-based' OCD change agency practice discussed in the 33 Section 3 chapters. The third aim is to respond to the somewhat sceptical view expressed by Gary McLean and Sehoon Kim in Chapter 52 about the 'reality' of EBOCD ever emerging beyond the examples of EBOCD illustrated in this book, due to the current persistent focus on Mode 1 research in management and organization studies that lacks practical relevance and utility. We offer a more positive and optimistic perspective by drawing attention to the wide range of extant OCD-related 'best evidence' that informed the change agency of our Section 3 reflective case history authors. The fourth and final aim is to present an 'EBOCD Conceptual Process Model' which the first author of this chapter has derived from the 'OCD Conceptual Framework' he offered in a chapter he contributed to the Hamlin, Keep and Ash (2001) book on Organizational Change and Development: A Reflective Guide for Managers, Trainers and Developers (see Hamlin, 2001). It depicts the similarities and connections between the processes of relevant, robust, rigorous and ethical internal Mode 2 research (including action research, design science research, professional partnership research and other forms of collaborative management research irrespective of whether conducted by internal or external consultants acting as change agents), and the processes of change management consultancy. These connections can open up opportunities for the generation of the types of instrumental knowledge and 'best evidence' called for by Hamlin in Chapter 1 and by McLean and Kim in Chapter 52 respectively, and thereby contribute to a bridging of the reputed 'research-practice' gap in HRD in general (see Hughes \& Gosney, 2016) and OCD in particular (see Hamlin, 2016). Such Mode 2 research can also open up opportunities for 'practice-to-theory' research and the eventual development of OCD-related conceptual knowledge through subsequent Mode 1 studies.

\section{COMPARING THE SECTION 2 PRACTITIONER PERSPECTIVES}

The chapter contributions in Section 2 presented a variety of critical reflections on EBOCD practice from authors who are: academics writing and researching about OCD of whom some have been engaged in collaborative academic and industry partnerships; internal or external OCD-related consultants; and others who have amassed both insider and outsider knowledge of OCD through their various roles. Many of these authors presented perspectives on cases of OCD initiatives that represented diverse sectors such as education, finance, and transportation. The change interventions ranged from training and coaching programmes, to quality management, culture change, strategic direction, data-driven decision-making, acquisitions, and applied theatre. Moreover, these contributions comprised an array of perspectives on evidence-based practice (EBP) associated with OCD initiatives in a wide range of Anglo and non-Anglo countries including Australia, Brazil, Germany, Italy, Palestine, the United Kingdom (UK) and many other countries.

A synthesis based upon our readings of these contributions suggests that there are four important factors that influence effective organizational change (OC) which are consistent with existing literature. These factors include: 'context', 'leadership, 'communication', and 'collaboration'. Furthermore, our review of their 'critical reflections' upon EBOCD practice suggest that these authors had demonstrated their commitment to EBP through: their use of literature to inform their practice; the use of models, frameworks, and theories to underpin their practice; the collection of data to inform their practice; and critical reflection and introspection to enhance their practice. 


\section{Concluding Reflections and Presentation of an EBOCD Conceptual Process Model}

- Context: The importance of understanding and being attuned to context was a theme that was consistent across these contributions. The majority of the authors in Section 2 mentioned environmental and organizational contexts and increasing internal and external workplace pressures that impact change. Turner (Chapter 13) discussed the changing business environment which he characterized as being volatile, uncertain, complex and ambiguous, and the effect this has had on 'C-suite' behaviours and expectations. Similarly, Leiber (Chapter 16) and Fernandes (Chapter 10) acknowledged the increasing focus on accountability within the educational sector. Pereira et al. (Chapter 15) mentioned market conditions that favoured the acquisition they discussed. Other reflections in relation to context involved the need to evaluate the context (Fernandes - Chapter 10; Pereira et al - Chapter 15), to align strategy within the context (Jackson \& Burnes - Chapter 11), to invest in learning and development (Ferrari - Chapter 17) particularly within higher levels of leadership (Martin - Chapter 12; Turner - Chapter 13) which will then lead to increased individual and organizational readiness to change (Ferrari - Chapter 17), to have internal change agents who are attuned to the organizational context and culture (Akella \& Khoury - Chapter 18), and to ensure attention is paid to the organizational history (Ferrari - Chapter 17).

- Leadership: The importance of leadership resonated throughout these contributions in terms of leaders being committed and supportive of change endeavours (Akella \& Khoury - Chapter 18; Leiber - Chapter 16), taking ownership and responsibility for the desired change, (Turner - Chapter 13), along with the points that leaders need to be competent change agents, and that such competence may need to be developed (Pereira et al. - Chapter 15). Fernandes (Chapter 10) stated that leadership is about influencing others to make better decisions, but acknowledged that all leaders are capable of making poor decisions. The consequences of leaders making hasty decisions is reflected on by Pereira et al. (Chapter 15) where not enough time was devoted to the analysis of people and their roles, leaving knowledge gaps which led to change synergies taking longer to realise. Martin (Chapter 12) suggested that the top leadership qualities included being honest, competent, inspiring and forward-looking. He suggested that change practitioners should also be 'ready and able to lead from the front' and to demonstrate these essential qualities. Additionally, he discussed the leadership 'merry go-round' whereby constant changes at the top disrupt reactions and the flow of change, over time. Turner's (Chapter 13) case study demonstrated links between leadership behaviour, specifically coaching skills, with organisational culture, employee engagement and performance. Turner stated that there needs to be a good understanding of the leadership DNA and that within this, leaders need to empower employees towards action. He also indicated that developing leaders to adopt a coaching style and to role model behaviours was necessary for effective change.

- Communication: Jackson and Burnes (Chapter 11) acknowledged that the more successful change programmes are those where a communication approach is used that ensures value alignment among those implementing the change, those impacted by the change process, and the type of change process that is being implemented. Informed by the Graves $(1970,1974)$ Emergent Cyclical Levels of Existence Theory (ECLET) Framework they suggest that individuals are influenced by a number of different value systems (first and second tier values) and these may change over time. They contend that change agents should identify values behaviours, and become attuned to value signals that can help to identify a values system. Doing so, they suggest, can create alignment that enables communication to be more effective which can facilitate engagement and cooperation instead of resistance. Turner (Chapter 13) also makes the point that organizational 
culture and the values within it help to drive the 'organizational mantra.' Fernandes (Chapter 10) acknowledged the importance of an open and communicative organizational culture. Similarly, Pereira et al. (Chapter 15) advocated for the importance of intense and opportune communication, and Leiber (Chapter 16) indicated that communications should be open and transparent. Lastly, Akella and Khoury (Chapter 18) made the point that successful change needs communication and involvement at all levels. They assert that having a better understanding of the organisational culture and the values system within it will help the organization to: a) better address resistance to change which is a phenomenon that is a shared responsibility among change agents and change recipients; and b) more effectively communicate, implement and embed change.

- Collaboration: The importance of involving organizational members, promoting participation and enabling collaboration was also a consistent theme across these contributions (Pereira et al. - Chapter 15). Fernandes (Chapter 10) referred to creating a climate of sharing and 'knowledge brokering' to help improve and embed leadership decision making. Further, Fernandes acknowledged that the use of data teams may facilitate collaborative decision making. Turner (Chapter 13) mentioned having an agreed 'route map' from the top level and insists that the change messages need to come from 'one team' only. Vaz and Clarke (Chapter 14) discussed how using 'applied theatre' as an intervention can support individuals, managers and leaders within organizations to collectively navigate change, through creating a safe place to work and to share emotions, feelings, and reflections with others. This intervention relies heavily on participation and engagement and the creation of a safe space to enable participants to understand their emotional responses to change which may influence the ability to respond more effectively to it. Lastly, Lieber (Chapter 16) suggested that using quality management could be a way to bring together other systems and processes into one core quality system approach.

In conclusion, these four factors, 'context', 'leadership', 'communication', and 'collaboration' which are consistent with existing literature, are often considered those factors that can enable effective organizational change but are also those factors that can paradoxically hinder organizational change. Moreover, these chapter contributors also acknowledged how they embraced evidence-based practice (EBP) in their OCD endeavours. Specifically, the use of existing OCD literature to inform practice was consistent across these contributions, as was the use of models, frameworks and theories such as the ECLET, the Kotter and Burke-Litwin models, and systems theory along with data collection through 360 degree feedback, and the use of previously validated survey instruments and assessments along with action research approaches. Lastly, the importance of being a reflective OCD practitioner who engages in critical reflection and introspection were especially reiterated by Ferrari (Chapter 17) and Akella and Khoury (Chapter 18). As will be appreciated, the significance of the four factors discussed above has been well illustrated in many of the 33 'reflective case histories' presented in Section 3 of this book.

\section{COMPARING THE SECTION 3 REFLECTIVE CASE HISTORIES}

Reflecting upon the set of 10 common 'insights' and 'lessons' about OCD practice that Hamlin (2001) deduced from 18 'critically reflective', 'research-informed' and in some instances 'evidence-based' case histories as published in Organizational Change and Development; A Reflective Guide for Managers, Trainers and Developers (Hamlin, Keep \& Ash, 2001) (See Table 1), we concluded it would be ap- 


\section{Concluding Reflections and Presentation of an EBOCD Conceptual Process Model}

Table 1. Past common insights/lessons (CILs) about effective OCD and research-informed and evidencebased change agency

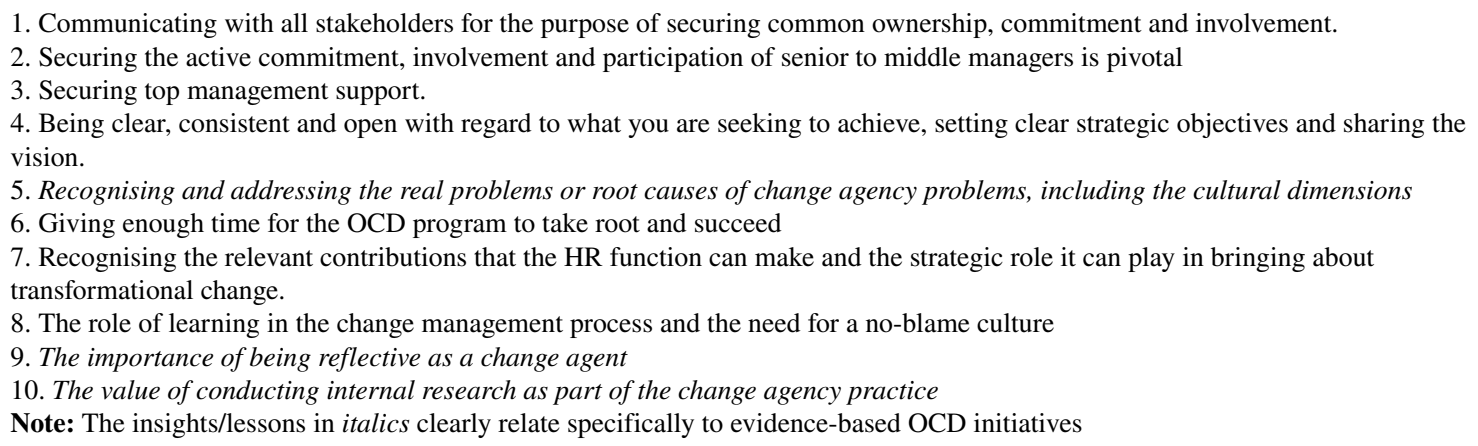

Source: Hamlin, R. G. (2001)

propriate to conduct a qualitative multiple cross-case comparative analysis (MCCCA) of the reflective case histories of specific OCD initiatives in single organization contexts as described by the authors of the Section 3 chapters, using these 'original' common insights and lessons (CILs) as deductive coding categories. The primary aim of the MCCCA was to search for commonalities and relative generalizations across the case histories, and assess the extent to which the findings from our examination supported the directly comparable findings that had resulted from Hamlin's (2001) equivalent study conducted 18 years or so ago. The secondary aim of the analysis was to identify (if possible) emergent 'new' CILs about effective OCD initiatives and evidence-based change agency.

As readers will recall in the Introduction to Section 3 of this book, we invited the chapter authors to make explicit the main 'insights' and 'lessons' (ILs) to be gained/learned by readers from their stories of, and critical reflections upon, their personal OCD change agency practice whether or not they had considered at the time that the OCD initiative had been 'research-informed' or 'evidence-based'. Although we asked them to summarize these ILs in the 'concluding reflections' section of their case history, we assumed other ILs might also be identifiable within the 'main text'. Hence, we subjected the entire content of each Section 3 reflective case history to qualitative theoretical coding. This involved using open coding at the first level of analytic abstraction to disentangle the data line-by-line and sentence-by-sentence, and thereby identify segments (key words, phrases and sentences) that could be expressed in the form of concepts (units of meaning) to which codes could be attached (Flick, 2014). The disentangled expressions which could be identified as 'insights' or 'lessons' were classified and deductively mapped against the 'original' CILs identified by Hamlin (2001). The ILs that could not be mapped were subsequently subjected to inductive axial coding to differentiate and group them into categories and thereby identify (if possible) a set of emergent 'new' CILs. This process involved searching for evidence of sameness, similarity or congruent meaning between the codes. Sameness was deemed to exist when the codes of two or more units of meaning were identical or near identical. Similarity was deemed to exist when the sentences and/or phrases of the coded concepts were different, but the kind of meaning was the same. Congruence existed where there was an element of sameness or similarity between the compared coded concepts. 


\section{Validating the 'Original' CILs and Identifying Emergent 'New' CILs}

The results of the MCCCA of the Section 3 reflective case histories are shown in the form of a grid (see Table 2). For each case history the ' $x$ ' in a grid box indicates those 'original' CILs that are supported and thus validated by one or more ILs identified within the 'concluding reflections' section of that case history. The ' $y$ ' in a grid box indicates those 'original' CILs that are supported by one or more ILs from both the 'main text' and the 'concluding reflections' section. And the ' $\mathrm{z}$ ' in a grid box indicates those 'original' CILs supported by evidence from the 'main text' section only. The overall numbers of compared Section 3 reflective case histories that contain evidence which empirically validate each of the 10 'original' CILs are shown at the bottom of the table.

Table 2. Result of MCCCA of the Section 3 chapters (reflective case histories)

\begin{tabular}{|c|c|c|c|c|c|c|c|c|c|c|c|c|c|c|c|}
\hline \multicolumn{2}{|c|}{ Case Histories (CHs) } & \multicolumn{10}{|c|}{$\begin{array}{c}\text { Original Common ‘Insights' and 'Lessons' Learned (CILs) } \\
\text { (Hamlin, 2001) }\end{array}$} & \multicolumn{4}{|c|}{$\begin{array}{c}\text { Number and Types of } \\
\text { OCD-Related 'Best } \\
\text { Evidence' References Cited } \\
\text { in the CHs }\end{array}$} \\
\hline Lead Authors & $\begin{array}{c}\text { Chptr } \\
\text { No. }\end{array}$ & 1 & 2 & 3 & 4 & 5 & 6 & 7 & 8 & 9 & 10 & $\mathbf{a}$ & b & c & d \\
\hline \multicolumn{16}{|c|}{ Reflective Case Histories From New Zealand and the UK } \\
\hline G. Greenwood & 19 & $\mathbf{z}$ & $\mathbf{z}$ & $\mathbf{z}$ & & & & & & & & 4 & 1 & 3 & \\
\hline D.Devins & 20 & $\mathbf{y}$ & $\mathbf{y}$ & & $\mathbf{y}$ & $\mathbf{y}$ & & $\mathbf{x}$ & & & $\mathbf{y}$ & 3 & & & 1 \\
\hline K Hatton & 21 & $\mathbf{x}$ & $\mathbf{x}$ & $\mathbf{x}$ & $\mathbf{x}$ & & $\mathbf{x}$ & & $\mathbf{x}$ & $\mathbf{y}$ & $\mathbf{y}$ & 1 & & 1 & 5 \\
\hline R. Holden & 22 & $\mathbf{y}$ & $\mathbf{y}$ & $\mathbf{y}$ & & & & & & & $\mathbf{z}$ & 9 & 1 & 5 & 2 \\
\hline R Jahnke & 23 & $\mathbf{y}$ & & $\mathbf{y}$ & $\mathbf{y}$ & & $\mathbf{x}$ & & $\mathbf{x}$ & $\mathbf{x}$ & & 3 & & & \\
\hline T. Kibble & 24 & $\mathbf{x}$ & & $\mathbf{x}$ & $\mathbf{x}$ & & $\mathbf{z}$ & $\mathbf{y}$ & $\mathbf{z}$ & & $\mathbf{z}$ & 3 & 1 & 2 & \\
\hline S. Lawson & 25 & $\mathbf{x}$ & $\mathbf{x}$ & & $\mathbf{x}$ & & $\mathbf{x}$ & & $\mathbf{y}$ & $\mathbf{y}$ & $\mathbf{y}$ & 4 & 9 & & 3 \\
\hline C. Lees & 26 & & & & & & $\mathbf{x}$ & & $\mathbf{z}$ & $\mathbf{z}$ & & 7 & 1 & 12 & \\
\hline B. D'Souza & 27 & $\mathbf{x}$ & $\mathbf{x}$ & $\mathbf{x}$ & $\mathbf{z}$ & & $\mathbf{x}$ & & $\mathbf{y}$ & $\mathbf{y}$ & $\mathbf{z}$ & 2 & 6 & 1 & \\
\hline P.Watt & 28 & & & $\mathbf{z}$ & & $\mathbf{z}$ & & & $\mathbf{y}$ & $\mathbf{y}$ & $\mathbf{y}$ & & 5 & 1 & 4 \\
\hline \multicolumn{16}{|c|}{ Reflective Case Histories From the USA } \\
\hline J. Baaki & 29 & $\mathbf{y}$ & $\mathbf{y}$ & & $\mathbf{y}$ & & $\mathbf{y}$ & & $\mathbf{y}$ & $\mathbf{y}$ & $\mathbf{z}$ & 4 & & & \\
\hline A Church & 30 & $\mathbf{y}$ & $\mathbf{y}$ & & & & $\mathbf{y}$ & & & & $\mathbf{z}$ & 6 & & 2 & 3 \\
\hline D. Drake & 31 & $\mathbf{x}$ & $\mathbf{y}$ & $\mathbf{y}$ & & $\mathbf{y}$ & & & $\mathbf{x}$ & & $\mathbf{x}$ & 5 & 1 & 1 & \\
\hline T Egan & 32 & $\mathbf{z}$ & & & $\mathbf{x}$ & & & & & $\mathbf{x}$ & $\mathbf{y}$ & 2 & 3 & 6 & \\
\hline J. Flesher & 33 & $\mathbf{z}$ & $\mathbf{x}$ & & $\mathbf{x}$ & & & & $\mathbf{x}$ & $\mathbf{x}$ & $\mathbf{x}$ & 3 & 3 & & \\
\hline J O.'Neill & 34 & & & $\mathbf{x}$ & & & $\mathbf{x}$ & & $\mathbf{y}$ & $\mathbf{z}$ & $\mathbf{z}$ & 2 & 4 & & 1 \\
\hline L. Quast & 35 & $\mathbf{x}$ & $\mathbf{y}$ & $\mathbf{y}$ & $\mathbf{x}$ & $\mathbf{y}$ & $\mathbf{x}$ & $\mathbf{x}$ & $\mathbf{y}$ & $\mathbf{x}$ & $\mathbf{x}$ & 14 & 9 & 24 & 2 \\
\hline T Shindell & 36 & $\mathbf{x}$ & $\mathbf{x}$ & $\mathbf{z}$ & $\mathbf{y}$ & & & $\mathbf{x}$ & & $\mathbf{x}$ & $\mathbf{y}$ & 1 & 2 & & \\
\hline \multicolumn{16}{|c|}{ Reflective Case Histories From Non-Anglo Countries } \\
\hline M. Woodbridge & 37 & $\mathbf{y}$ & $\mathbf{y}$ & & $\mathbf{x}$ & & $\mathbf{y}$ & $\mathbf{z}$ & & & $\mathbf{x}$ & 6 & & 1 & \\
\hline N. Jaspers & 38 & $\mathbf{y}$ & $\mathbf{y}$ & $\mathbf{y}$ & $\mathbf{x}$ & $\mathbf{z}$ & $\mathbf{x}$ & $\mathbf{x}$ & $\mathbf{y}$ & & $\mathbf{x}$ & 2 & 1 & & 3 \\
\hline V. Pathak & 39 & $\mathbf{x}$ & $\mathbf{x}$ & & & $\mathbf{x}$ & $\mathbf{x}$ & & & $\mathbf{x}$ & $\mathbf{x}$ & 2 & & 1 & 1 \\
\hline
\end{tabular}


Table 2. Continued

\begin{tabular}{|c|c|c|c|c|c|c|c|c|c|c|c|c|c|c|c|}
\hline \multicolumn{2}{|c|}{ Case Histories (CHs) } & \multicolumn{10}{|c|}{$\begin{array}{c}\text { Original Common 'Insights' and 'Lessons' Learned (CILs) } \\
\text { (Hamlin, 2001) }\end{array}$} & \multicolumn{4}{|c|}{$\begin{array}{l}\text { Number and Types of } \\
\text { OCD-Related 'Best } \\
\text { Evidence' References Cited } \\
\text { in the CHs }\end{array}$} \\
\hline Lead Authors & $\begin{array}{l}\text { Chptr } \\
\text { No. }\end{array}$ & 1 & 2 & 3 & 4 & 5 & 6 & 7 & 8 & 9 & 10 & $\mathbf{a}$ & $\mathbf{b}$ & c & d \\
\hline F. Ferrari & 40 & & & & & $\mathbf{y}$ & & & & $\mathbf{y}$ & $\mathbf{y}$ & 5 & & 6 & \\
\hline C. Saliba & 41 & $\mathbf{y}$ & $\mathbf{x}$ & $\mathbf{y}$ & $\mathbf{x}$ & $\mathbf{x}$ & & & & & & 5 & & & \\
\hline M. Loon & 42 & $\mathbf{y}$ & $\mathbf{x}$ & & & & & & & & & 4 & 2 & 3 & 1 \\
\hline M. Boonen & 43 & & $\mathbf{x}$ & & $\mathbf{x}$ & $\mathbf{z}$ & $\mathbf{x}$ & & $\mathbf{z}$ & $\mathbf{y}$ & & 5 & 3 & & 2 \\
\hline G.Brekelmans & 44 & $\mathbf{y}$ & $\mathbf{y}$ & $\mathbf{y}$ & $\mathbf{x}$ & $\mathbf{z}$ & $\mathbf{x}$ & & & $\mathbf{x}$ & & 4 & 2 & & \\
\hline C Ehlen & 45 & $\mathbf{x}$ & $\mathbf{x}$ & $\mathbf{y}$ & & & $\mathbf{x}$ & & & $\mathbf{x}$ & $\mathbf{z}$ & & 2 & & 2 \\
\hline W. ten Have & 46 & & & & & $\mathbf{z}$ & $\mathbf{x}$ & & & $\mathbf{z}$ & $\mathbf{x}$ & 4 & 3 & 5 & \\
\hline D. Ropes & 47 & $\mathbf{x}$ & $\mathbf{x}$ & & $\mathbf{x}$ & $\mathbf{y}$ & $\mathbf{x}$ & & $\mathbf{y}$ & $\mathbf{x}$ & & 1 & 1 & 2 & 1 \\
\hline J. Farinha & 48 & $\mathbf{x}$ & & & & & & & & $\mathbf{x}$ & $\mathbf{x}$ & 2 & 4 & 3 & \\
\hline S Lau & 49 & $\mathbf{y}$ & $\mathbf{z}$ & & & $\mathbf{y}$ & $\mathbf{x}$ & & $\mathbf{y}$ & $\mathbf{x}$ & $\mathbf{y}$ & 1 & & 1 & 1 \\
\hline K Watkins & 50 & $\mathbf{y}$ & $\mathbf{y}$ & $\mathbf{z}$ & & & $\mathbf{x}$ & & $\mathbf{y}$ & & $\mathbf{y}$ & 1 & 4 & 2 & 3 \\
\hline K Dirani & 51 & $\mathrm{y}$ & $\mathrm{x}$ & & $\mathrm{y}$ & & $\mathrm{y}$ & & $\mathrm{y}$ & $\mathrm{x}$ & & 1 & 1 & 2 & \\
\hline No. of CHs & & 27 & 24 & 16 & 18 & 13 & 21 & 6 & 18 & 22 & 24 & & & & \\
\hline No. of Refs & & & & & & & & & & & & 116 & 69 & 84 & 35 \\
\hline
\end{tabular}

*CILs Categories: ' $x$ ' denotes supporting evidence from 'concluding reflections' only; ' $y$ ' denotes supporting evidence from concluding reflections and main text; and ' $\mathrm{z}$ ' denotes supporting evidence from main text only

**Types of OCD Best Evidence Publications in the Reference Lists of the CHs: 'a' change management/OCD books/handbooks \& HBR; 'b' books/articles on specific OCD related theories and models; 'c' articles on OCD related Mode 1 and generalised Mode 2 research; 'd' articles/reports on organization/sector-specific Mode 2 research or investigation

Overall, the authors of 27 of the 33 (81.82\%) Section 3 case histories identified aspects of Communicating with all stakeholders for the purpose of securing common ownership, commitment and involvement [in the change facilitation process] as a key insight/lesson regarding effective OCD and EBOCD change agency practice. The next two most supported 'original' CILs were: Securing the active commitment, involvement and participation of senior to middle managers, and The value of conducting internal research as part of the change agency practice with the authors of $72.73 \%(n=24)$ of the case histories having identified various aspects of these two respective coding categories in the 'main text' and 'concluding reflections' section of their respective stories. Five of the other 'original' CILs were supported by over (or just under) $50 \%$ of the case histories, namely: The importance of being reflective as a change agent (22 of 33); Giving enough time for the OCD programme to take root and succeed (21 of 33); Being clear, consistent and open with regard to what you are seeking to achieve, setting clear strategic objectives and sharing the vision (18 of 33); The role of learning in the change management process and the need for a no-blame culture (18 of 33); and Securing top management support (16 of 33). It is noticeable that Recognising and addressing the real problems or root causes of change agency problems, including the cultural dimension was supported by only $39.39 \%(n=13)$ of the case histories. The reason for this may be due to the fact that most of the OCD practitioner authors of the Section 3 case histories had acted in the role of internal change agents and may have already identified the real 


\section{Concluding Reflections and Presentation of an EBOCD Conceptual Process Model}

problems and root causes for the change, or they had been external consultants who had been working with the change managers in collaborative partnership from the time the OCD initiative had been first triggered by a problem where its root cause was not in question. However, we suggest this 'original' CIL, which is relevant to all external management consultants at the contracting phase of a new 'consultantclient' relationship, should not be thought of as anything less crucial than any of the more supported CILs. Surprisingly, the CIL Recognising the relevant contributions that the HR function can make and the strategic role it can play in bringing about transformational change was supported by just $18.18 \%$ $(n=6)$ of the case histories. This limited supporting evidence might be a reflection of the negative view that many line managers have of the HR function and of HR professionals in general, as discussed by Hamlin in Chapter 1.

The axial coding of the ILs resulting from the MCCCA that could not be mapped against the 10 'original' CILs led to the emergence of 10 'new' CILs as shown in bold typeface in Table 3 together with the respective cluster of underpinning ILs. In summary, the results suggest that OCD practitioners should:

1. Create a vision and set of values that engage everyone

2. Allow participative 'bottom up' initiatives in the change process

3. Adopt a shared/distributive leadership approach

4. Engage participants affected by the change by giving them voice, using their expertise, involving them, and treating them as active collaborative partners

5. Recognise the power of trust and build on it

6. Use theory and models as change agency tools, and draw upon sources of 'best evidence' to inform and guide OCD processes

7. Ensure understanding of individuals' interests and the power relationship between those involved in the change, and also respect their perspectives

8. Ensure collaboration between external (or internal) change consultants and the internal client change agents

9. Ensure all change agents involved in the OCD processes become fully skilled and act as a team

10. Ensure the 'soft' social/interpersonal relations/cultural aspects of OCD are given as much attention as the 'hard' strategy, structure and systems aspects

Table 3. Emergent new common 'insights' and 'lessons' (CILs) and underpinning ILs

\begin{tabular}{|l|c|}
\hline \multicolumn{1}{|c|}{ Emergent New Common 'Insights' and 'Lessons' (CILs) and Underpinning ILs } & $\begin{array}{c}\text { Chapter } \\
\text { Nos. }\end{array}$ \\
\hline 1. Create a vision and set of values that engage everyone & 20 \\
\hline Need to create a vision which in turn produces a strategy [20] & 25 \\
Developing a unifying vision [25] & 43 \\
Strive to ensure there is a clear vision for the OCD initiative at the top of the organization [43] & 22 \\
\hline Created a unified mission and values statement describing the desired future state for the plant [22]. & 30 \\
But applied learning about the change vision and associated policy [25] & \\
Develop clarity in vision where values are shared with people [30] & \\
\hline
\end{tabular}




\section{Concluding Reflections and Presentation of an EBOCD Conceptual Process Model}

\section{Table 3. Continued}

Emergent New Common 'Insights' and 'Lessons' (CILs) and Underpinning ILs

At the start of the culture transformation, senior executives participated in the development of a company-wide set of shared values to establish the language and the foundation for the culture shift. The core values are the organization's goals, strategies, and philosophies that the organization advocates about itself [35]

A vision was created for the future [38]

Phase-I (Strategize) was dedicated to setting the vision and strategy of transformation, and it comprised of a series of family retreats to discuss and agree on the shape, timing, and goals of transformation [41] Management thinkers [change leaders] should develop an appealing vision [46]

2. Allow participative 'bottom up' initiatives in the change process

Adopt bottom-up OCD approach which engages multiple stakeholders in the detail of change [20]

Use inputs from internal client feedback [29]

Allow and encourage 'bottom-up' change initiatives rather than dictating change and plans through a 'top down' command and control environment [35]

Avoid using OCD methods that are too much 'top-down' driven and facilitated 'at a distance' [i.e. allow some 'bottom-up' facilitation] [45]

We utilise the 'inputs from internal client feedback [29]

Use an agile and accountable 'campfire' (self-managed) approach [by employees affected] [31]

Additional employee involvement and support was through the creation of a grass-roots [bottom-up] change agent community [35]

Another objective was to get feedback on the policy that could be processed by the core team. [38]

All internal stakeholders had important roles to play in this project [38]

The big difference compared to prior projects was that this was initiated in a dual form (top-down and bottom up) [43]

An action research approach that engaged stakeholders in first creating indigenous evidence of the need for change with an eye toward involving them in generating [bottom up] the changes signalled by that evidence. [50]

\section{Adopt a shared/distributive leadership approach}

Recognize need for shared leadership with 'connections', 'conversations' and 'knowledge' at its heart [22]

Recognize need for distributed leadership and systems thinking in bringing about changes that will challenge the identity of many individuals [49]

Towards shared leadership [22]

Each team nominated a coaching champion who was responsible for bringing this work [i.e. embedding a coaching culture] alive in their team [by serving] in many ways as an entrepreneur [31]

Line managers were empowered to make many autonomous decisions.... and expected to mentor his or her subordinates to have a clear understanding of their roles [51]

4. Engage participants affected by the change by giving them voice, using their expertise, involving them, and treating them as active collaborative partners

A crucial stage of the planned change process is evident in this case- the need for involvement, sharing, and commitment [19]

Recognize it is about ways of working for and with people as equal partners in the change processes [25]

Change leaders and participants (stakeholders) should become partners in facilitating the OCD [33]

Stakeholders to move from being passive 'customers' to being active [participant] researchers and 'meaning-makers' [33]

It needed to give voice to the employee and promote key values such as fairness and honesty throughout all levels of the workforce [22]

A shift to a more collaborative change approach would address the underlying, structurally embedded tension between performance and experience [25] 


\section{Concluding Reflections and Presentation of an EBOCD Conceptual Process Model}

\section{Table 3. Continued}

\begin{tabular}{|c|c|}
\hline Emergent New Common 'Insights' and 'Lessons' (CILs) and Underpinning ILs & $\begin{array}{l}\text { Chapter } \\
\text { Nos. }\end{array}$ \\
\hline Place an emphasis on democratizing coaching so they [i.e. client organization/managers] own it [31] & 31 \\
\hline $\begin{array}{l}\text { The academy utilizes multiple learning strategies including learning and application modules, } 1: 1 \text { assessment and } \\
\text { coaching, and Action Learning teams and projects to foster rapid leadership development. The partnership of these three } \\
\text { groups made use of both practitioner expertise and local context [34] }\end{array}$ & 34 \\
\hline Involvement of employees throughout transformation [35] & 35 \\
\hline $\begin{array}{l}\text { Employees were involved throughout the culture transformation, from the creation of the organizational culture values to } \\
\text { the facilitation of culture workshops to the alignment of culture within human resources processes [35] }\end{array}$ & \\
\hline All internal stakeholders had important roles to play in this project [38] & 38 \\
\hline Another objective was to get feedback on the policy that could be processed by the core team [38] & \\
\hline $\begin{array}{l}\text { Phase-I (Strategize) was dedicated to setting the vision and strategy of transformation, and it comprised of a series of } \\
\text { family retreats to discuss and agree on the shape, timing, and goals of transformation [41] }\end{array}$ & 41 \\
\hline \multicolumn{2}{|l|}{ 5. Recognise the power of trust and build on it } \\
\hline Build on trust and not rely on control [43] & 43 \\
\hline Recognize the 'power of trust' which is the foundation of any relationship [49] & 49 \\
\hline Based on this trust, the owner approved the plan [47] & 47 \\
\hline \multicolumn{2}{|l|}{$\begin{array}{l}\text { 6. Use theory and models as change agency tools, and draw upon sources of 'best evidence' to inform and guide } \\
\text { OCD processes }\end{array}$} \\
\hline $\begin{array}{l}\text { Use management theory and frameworks to encourage debate and broaden the thinking of the respective stakeholders and } \\
\text { to help transfer responsibility for the OCD initiative to the Board (top management) [27] }\end{array}$ & 27 \\
\hline $\begin{array}{l}\text { Have one or several road maps (i.e theoretical perspectives) to guide the conceptualization and implementation of a change } \\
\text { process [30] }\end{array}$ & 30 \\
\hline Use theory and models as strategic analytical tools [32] & 32 \\
\hline $\begin{array}{l}\text { Use a combination of sources of 'best evidence' to inform the formulation and implementation of OC initiatives to ensure } \\
\text { a more appropriate and better context-situated decision-making process [40] }\end{array}$ & 40 \\
\hline Evidence was used to convince employees [20] & 20 \\
\hline $\begin{array}{l}\text { Before any tools were selected, research and evidence were sought on suitable tools that existed and that other } \\
\text { organizations similar to my own were using [21] }\end{array}$ & 21 \\
\hline Well-recognised coaching models, such as GROW, were also included [21] & \\
\hline $\begin{array}{l}\text { The latter saw the group engage "intellectually" with their master's level knowledge and understanding of classic models } \\
\text { of change (e.g. Burke \& Litwin, 1992; Kohtter, 1996). Such models were important in feeding the dialogue [22] }\end{array}$ & 22 \\
\hline Used insights that the Mckinsey 7 s model had laid bare [24] & 24 \\
\hline $\begin{array}{l}\text { Development is aligned with Morgan's (2007) pragmatic approach - considering what will work best in each situation? } \\
\text { [26] }\end{array}$ & 26 \\
\hline \multicolumn{2}{|l|}{$\begin{array}{l}\text { Grant's (2014) solution-based coaching is seen in my approach to the development and my clients vision of where she } \\
\text { needed to be [26] }\end{array}$} \\
\hline $\begin{array}{l}\text { As a starting point to answering my own questions, I turned to the theories of Hofstede (2011) and Nair \& Bhatnagar } \\
\text { (2011) which in turn provided me with a conceptual base to work from. [27] }\end{array}$ & 27 \\
\hline \multicolumn{2}{|l|}{$\begin{array}{l}\text { I then mapped my own and "temporary" role as change agent against Lippet, Watson, and Westley's } 7 \text { step change theory } \\
\text { framework (1958) and in doing so, a rich line of questioning and a general discussion evolved which focussed on change } \\
\text { objects, formulation of strategy and plans [27] }\end{array}$} \\
\hline $\begin{array}{l}\text { I introduced Belbin's Team Role Model (1993) to assist me in dissecting the roles, skills and behaviours necessary to } \\
\text { successfully manage a programme of change (9 Using Porter's Five Forces } \\
\text { framework [27] }\end{array}$ & \\
\hline
\end{tabular}




\section{Concluding Reflections and Presentation of an EBOCD Conceptual Process Model}

Table 3. Continued

\begin{tabular}{|c|c|}
\hline Emergent New Common 'Insights' and 'Lessons' (CILs) and Underpinning ILs & $\begin{array}{l}\text { Chapter } \\
\text { Nos. }\end{array}$ \\
\hline \multicolumn{2}{|l|}{$\begin{array}{l}\text { Grant's Resources (and Capabilities) framework (1991) was particularly useful for exposing the full extent of tangible } \\
\text { resources that would potentially be shared within the network [27] }\end{array}$} \\
\hline \multicolumn{2}{|l|}{$\begin{array}{l}\text { Hofstede and his cultural dimensions theory (1974) to explain and explore some of the tensions that may have been felt } \\
\text { because of cultural differences within the group [27] }\end{array}$} \\
\hline \multicolumn{2}{|l|}{$\begin{array}{l}\text { I employed the NLP (neuro linguistic programming) hierarchy of ideas framework attributed to Bandler \& Grinder, (1997) } \\
\text { and the linguistic tools of chunking up and down to control the flow of conversation from abstract to specific, and vice } \\
\text { versa until agreement was reached [27] }\end{array}$} \\
\hline \multirow{2}{*}{\multicolumn{2}{|c|}{$\begin{array}{l}\text { To provide a level of reassurance over the need to openly deal with difficult issues, I briefly discussed Tuckman and } \\
\text { Jensen's work on high performance teams (1965) which then sparked rich questioning and discussion focussed upon } \\
\text { emotional regulation and relationship management [27] }\end{array}$}} \\
\hline & \\
\hline \multicolumn{2}{|l|}{$\begin{array}{l}\text { Coaching sessions served a dual purpose of ironing out unresolved interpersonal challenges that manifested during the } \\
\text { initial one to one meetings and group work, and for exploring leadership styles and behaviours using trait, style, and } \\
\text { contingency theories [27] }\end{array}$} \\
\hline \multicolumn{2}{|l|}{$\begin{array}{l}\text { I made greater use of Lippet, Watson and Westley's } 7 \text { step change theory (1958) as it allowed me to focus their attention } \\
\text { more on their roles and responsibilities as change agents rather than on the evolution of the change itself [27] }\end{array}$} \\
\hline $\begin{array}{l}\text { The use of TAM as an analytical framework through which we could embark on a process of organizational sense-making } \\
\text { [28] }\end{array}$ & 28 \\
\hline $\begin{array}{l}\text { The underlying bases of how we conceptualize, identify and measure future potential are based on the latest thinking on } \\
\text { leadership potential in the field of I-O Psychology) and on Silzer and Church's (2009; 2014; 2017) Leadership Potential } \\
\text { BluePrint. [29] }\end{array}$ & 29 \\
\hline $\begin{array}{l}\text { The purpose of this yearlong change endeavor was not to test theoretical perspectives, but informed by them, to try to } \\
\text { introduce new concepts for the theatres to achieve the desired change [30] }\end{array}$ & 30 \\
\hline Use a simple model that can be scaled and leveraged in many ways [31] & 31 \\
\hline \multicolumn{2}{|l|}{ Possess a well-researched and grounded model of change and coaching [31] } \\
\hline $\begin{array}{l}\text { My practice, while always reflecting my training as a researcher and teacher, has become a flexible combination of models } \\
\text { and components [33] }\end{array}$ & 33 \\
\hline The APLA utilizes TLD Group's empirically-derived physician leadership competency model [34] & 34 \\
\hline The process began by looking for research-based methods or "best evidence" in the literature [36] & 36 \\
\hline $\begin{array}{l}\text { We regularly apply, mainly adapted for our specific needs, are: Six Sigma, Kaizen und Ischikawa from Japan; TRIZ from } \\
\text { Russia, Drexler-Sibbet from the USA [37] }\end{array}$ & 37 \\
\hline $\begin{array}{l}\text { This system is based upon Deming's Plan-Do-Check-Act (PDCA) cycle and is widely accepted and utilised by most of } \\
\text { industries worldwide. [39] }\end{array}$ & 39 \\
\hline $\begin{array}{l}\text { In addition, in defining the change communication path, HR based its work on Kotter's 'Eight Stages of Successful Large } \\
\text { Scale Change' (Kotter \& Cohen, 2002) to ensure that the project flowed systematically to reach its objectives [41] }\end{array}$ & 41 \\
\hline $\begin{array}{l}\text { The use of technical terms, and even change management concepts/labels and their semantics are important consideration } \\
\text { when attempting to communicate, and persuade the client and the project's stakeholders [42] }\end{array}$ & 42 \\
\hline $\begin{array}{l}\text { The project followed Burnes' description of organizational change using Lewin's model of unfreeze-change-refreeze } \\
\text { (Burnes, 2014) [43] }\end{array}$ & 43 \\
\hline \multicolumn{2}{|l|}{$\begin{array}{l}\text { This sentence was the start of a journey of organizational change combining the TPS principles with a human care } \\
\text { program [43] }\end{array}$} \\
\hline \multicolumn{2}{|l|}{$\begin{array}{l}\text { Because of the emphasis on technique and efficiency some members of management, inspired by The Theory of Presence } \\
\text { (Een Theorie van de Presentie, Baart, 2004) [43] }\end{array}$} \\
\hline $\begin{array}{l}\text { As a theoretical basis for this project a framework on the coherence of personal, interpersonal and organizational } \\
\text { capacities (Figure 1) in the school as an organization was used (Mitchell \& } \\
\text { Sackney, 2011) [45] }\end{array}$ & 45 \\
\hline
\end{tabular}




\section{Concluding Reflections and Presentation of an EBOCD Conceptual Process Model}

\section{Table 3. Continued}

\begin{tabular}{|c|c|}
\hline Emergent New Common 'Insights' and 'Lessons' (CILs) and Underpinning ILs & $\begin{array}{l}\text { Chapter } \\
\text { Nos. }\end{array}$ \\
\hline \multicolumn{2}{|l|}{$\begin{array}{l}\text { A new instrument, the "Co-Creation-Wheel", developed by Ehlen (2015), promised to offer that analytical support to its } \\
\text { users [45] }\end{array}$} \\
\hline $\begin{array}{l}\text { The question of what theoretical and/or empirical evidence actually underpins an idea or model are too quickly overlooked } \\
\text { [46] }\end{array}$ & 46 \\
\hline \multicolumn{2}{|l|}{$\begin{array}{l}\text { Management concepts can also provide a sense of direction, give you the possibility to find your way [and] gain insight } \\
\text { [46] }\end{array}$} \\
\hline \multicolumn{2}{|l|}{$\begin{array}{l}\text { Management models can also provide the necessary structure and support when learning something or realizing targets } \\
\text { [46] }\end{array}$} \\
\hline $\begin{array}{l}\text { Han found the approach of Lewin (1948) on social conflicts, and the method of the Search Conference of Emery and } \\
\text { Purser (1996) for planning organizational change [47] }\end{array}$ & 47 \\
\hline TFWT considered Weick and Quinn's (1999) Continuous Change perspective to be the most useful one to adopt [48] & 48 \\
\hline $\begin{array}{l}\text { He had been exploring complexity theory and other similar topics and was especially receptive to the idea of informal } \\
\text { learning [50] }\end{array}$ & 50 \\
\hline \multicolumn{2}{|l|}{$\begin{array}{l}\text { Watkins and Marsick's (1993) model of the learning organization was identified as a strong, evidence-based framework } \\
\text { fitted to the GHG context [50] }\end{array}$} \\
\hline \multicolumn{2}{|l|}{$\begin{array}{l}\text { 7. Ensure understanding of individuals' interests and the power relationship between those involved in the change, } \\
\text { and also respect their perspectives }\end{array}$} \\
\hline Mark claimed the biggest challenge is ensuring that everyone's problems are considered [19] & 19 \\
\hline Gain early insight of the individual interests and backstage political power of the involved actors [38] & 38 \\
\hline Explore the 'power' dynamics at play [44] & 44 \\
\hline Strive to understand the personal perspective of individual employees [48] & 48 \\
\hline $\begin{array}{l}\text { I facilitated a STEEP (sociological, technological, economic, ecological, and political) analysis of the far environment. } \\
\text { Discussion was rich with respect to emerging trends - especially at social and political levels [27] }\end{array}$ & 27 \\
\hline \multicolumn{2}{|l|}{$\begin{array}{l}\text { Stakeholder analysis and prioritisation using adapted frameworks of Patton and Comforth (1991) and Johnson and } \\
\text { Scholes (1993) provided me with a greater insight as to how potential partnerships along with their potential opportunities } \\
\& \text { threats could play out into the future [27] }\end{array}$} \\
\hline $\begin{array}{l}\text { How best to protect and secure organizational data? Early on in the process, treating the agency and its employees with } \\
\text { dignity and respect was a major concern [36] }\end{array}$ & 36 \\
\hline $\begin{array}{l}\text { Following Schein's approach, I began an open consultation process through which I suggested they first take a diagnostic } \\
\text { moment to understand better the attitude of the personnel involved in the change in progress [40] }\end{array}$ & 40 \\
\hline The Honduras case for instance, "power" played a major influential role [44] & 44 \\
\hline Shifting the power dynamics between the SLT and Top Team [49] & 49 \\
\hline \multicolumn{2}{|l|}{ 8. Ensure collaboration between external (or internal) change consultants and the internal client change agents } \\
\hline Ensure there is a clear process of collaboration between change agents and clients [30] & 30 \\
\hline Improve teamwork and cooperation amongst the change facilitators [32] & 32 \\
\hline $\begin{array}{l}\text { Encourage individual external consultant and the collective of internal change agents (i.e. the managers and HR team) to } \\
\text { engage in joint sense-making [38] }\end{array}$ & 38 \\
\hline $\begin{array}{l}\text { They [the coaching champions/change agents] were all linked to each other so they could compare notes to increase their } \\
\text { understanding of the [OCD] terrain, learn from their best practices (and mistakes) and riff off each other in creating new } \\
\text { ways to move toward the desired new culture [31] }\end{array}$ & 31 \\
\hline $\begin{array}{l}\text { At the same time, these solutions were the product of individual (the external consultant) and collective sense making (the } \\
\text { HR team) [38] }\end{array}$ & 38 \\
\hline
\end{tabular}


Table 3. Continued

\begin{tabular}{|c|c|}
\hline Emergent New Common 'Insights' and 'Lessons' (CILs) and Underpinning ILs & $\begin{array}{l}\text { Chapter } \\
\text { Nos. }\end{array}$ \\
\hline \multicolumn{2}{|l|}{ 9. Ensure all change agents involved in the OCD processes become fully skilled and act as a team } \\
\hline $\begin{array}{l}\text { Change agents ....must improve their ability to learn from one another, from related disciplines and the field as a whole if } \\
\text { coaching [in support of OCD] is to adapt in keeping up with the changing needs of clients [31] }\end{array}$ & 31 \\
\hline Improve teamwork and cooperation amongst the change facilitators [32] & 32 \\
\hline Equip front-line leaders (managers/supervisors) and functional professionals to facilitate change [43] & 43 \\
\hline A more collaborative approach to the change process [22] & 22 \\
\hline \multicolumn{2}{|l|}{$\begin{array}{l}\text { The workshops were designed to develop the group into a high performing team, one equipped with a collective capability } \\
\text { to lead the culture change initiative [22] }\end{array}$} \\
\hline $\begin{array}{l}\text { Back on track with Grant, an analysis of capabilities was restricted to focussing on upon leveraging core competencies } \\
\text { across organisations - skills, expertise, community knowledge, etc, together with the 'intrinsic' leadership qualities } \\
\text { deemed necessary and specific to the sector [27] }\end{array}$ & 27 \\
\hline $\begin{array}{l}\text { We felt it was paramount that HR [change] leaders in the field were better equipped to have in-depth discussions about the } \\
\text { nature if the predictive behavior change algorithms [in the change program] [29] }\end{array}$ & 29 \\
\hline Your alertness and ability to learn are core element s of an EBOCD approach [46] & 46 \\
\hline $\begin{array}{l}\text { Reflecting on how the TFWT had functioned, the members increasingly came to realize that the word "team" was the } \\
\text { important and vital word for this kind of OCD project [48] }\end{array}$ & 48 \\
\hline \multicolumn{2}{|l|}{$\begin{array}{l}\text { 10. Ensure the 'soft' social/interpersonal relations/cultural aspects of OCD are given as much attention as the } \\
\text { 'hard' strategy, structure and systems aspects }\end{array}$} \\
\hline Recognition in maintaining and sustaining these relationships is still important [19] & 19 \\
\hline \multicolumn{2}{|l|}{ This case however has demonstrated the need to reconceive workplace relationships [19] } \\
\hline $\begin{array}{l}\text { Focus as much on the 'soft' issues affected (e.g. culture', interpersonal relationships) as on the 'hard' issues affected by the } \\
\text { OCD initiative [32] }\end{array}$ & 32 \\
\hline Do not ignore the basic social aspects of work that OCD initiatives will impact/disturb [47] & 47 \\
\hline Insufficient attention is given to the behavioural aspects of change management [24] & 24 \\
\hline \multicolumn{2}{|l|}{ And to the interpersonal communication skills required for managing change effectively [24] } \\
\hline $\begin{array}{l}\text { Workforce potential, individually and together, may too often be overlooked during change when positioned as 'associated } \\
\text { people issues' or 'soft issues of management' [25] }\end{array}$ & 25 \\
\hline Sharon recognised the importance of soft skills and people development [26] & 26 \\
\hline
\end{tabular}

Note: The ILs in normal typeface were identified in the 'Concluding Reflections' section of the reflective case histories whereas the italicized ILs were identified in the 'Main Text'.

Of the 10 'original' CILs obtained from Hamlin's (2001) study in Hamlin, Keep and Ash (2001), three of them (Numbers 5, $9 \& 10$ ) clearly relate specifically to EBOCD initiatives, whereas the others could be regarded as relevant to all OCD initiatives and change agency approaches. In addition to providing empirical validation of these three 'original' CILs, our MCCCA examination has led to the identification of one 'new' CIL that relates specifically to evidence-based change agency practice, namely No.6: Use theory and models as change agency tools, and sources of 'best evidence' to inform and guide OCD processes (see Table 3 ). 


\section{REFLECTING ON THE 'REALITY' OF EBOCD IN PRACTICE}

The 33 'reflective case histories' presented in Section 3 are indicative of the 'reality' of EBOCD in the world of practice, and demonstrate that EBOCD is not merely 'rhetoric' emanating from the world of academe. For us it is encouraging to see the extent and range of 'best evidence' that these EBOCD practitioners have drawn upon from literature to inform, shape and critically evaluate their OCD initiatives and change agency practices. Across the 33 case histories a total of 501 published works have been cited of which 304 are directly related to OCD issues. Of these, 116 (38.16\%) are OCD and change management related books/handbooks or magazines including the Harvard Business Review (HBR); 69 (22.70\%) are books and journal articles on OCD-related theories and models; 84 (27.63\%) are journal articles reporting OCD-related generalized Mode 1 and context-general Mode 2 empirical research findings, and $35(11.51 \%)$ are journal articles or other publications reporting the results of context-specific (i.e., organization-specific or sector-specific) OCD-related Mode 2 research or management investigations focused on 'hard fact' data gathering to inform managerial decision-making. Thus, we conclude there is an existing and sizable body of 'best evidence' of variable strengths currently available for OCD practitioners to draw upon if so inclined to become more research informed and evidence-based. As can be deduced from Table 2, the authors of $93.94 \%(n=31)$ of the Section 3 case histories have used and cited various OCD and other change management related books as recorded in their critical reflective stories of change agency practice. As can also be deduced from Table 2, the authors of $69.70 \%(n=23)$ of the case histories have cited publications describing and discussing the specific OCD-related theories and models that they had used as tools for managing/facilitating change; and the authors of $63.64 \%(n=21)$ of the case histories have cited publications on OCD related generalised Mode 1 or Mode 2 research which they had used to inform and shape their EBOCD initiatives. Furthermore, the authors of $48.48 \%$ $(n=16)$ of the case histories indicate organization-specific research was used to inform and shape their OCD initiatives. However, as Hamlin argues in Chapter 1, the overall body of extant OCD-related 'best evidence' is small compared to other areas of management/leadership study and practice, and consequently there is a need for far more conventional Mode 1 research that is designed to: a) gain a better relational understanding of those generic factors found within many if not most organizations which have the potential to either help or hinder OCD processes, and b) generate (if possible) generalizable conceptual knowledge that has relevance and utility across multiple organizational settings. Additionally, as Hamlin also argues, there is a need for other paradigmatic approaches such as those based on pragmatism and mixed-method research. These include notions of Mode 2 research for generating context-specific instrumental knowledge for direct application, and of Mode 2 replication research studies that explore OCD-related issues which are common to many organizations with the aim of developing mid-range theory from practice through replication logic and multiple cross-case comparative analysis (Eisenhardt, 1989; Tsang \& Kwan, 1999).

Hamlin's call in Chapter 1 for replication research is echoed by Mclean and Kim in Chapter 52, who, relating their views and arguments especially to Mode I research, claim that regardless of the research paradigm used, whether based on positivistic, post-positivistic or relativistic assumptions, it is 'difficult (if not impossible) to generate knowledge that is likely to be accepted as evidence which can be applied broadly'. They believe that a major limitation to what they refer to as emerging EBOCD is the existing research paradigms associated with publications, and that this calls for a shift in mind-set on the part of university administrators, journal editors and editorial boards, and authors. Furthermore, they argue that replicated research needs to be valued and encouraged because it is through replicability 
that knowledge becomes acceptable as 'evidence'. In this regard it is encouraging to note that various mainstream management journals have begun to welcome articles reporting the results of replication research (see for example Antonakis, 2017; Bettis, et al.; 2016). Similar to Hamlin's argument in Chapter 1, Joan van Aken argues in Chapter 5 that if single organization design science studies are replicated in other specific organizational settings, and the resulting sets of instrumental knowledge are subjected to multiple cross-case comparative analyses, then these can lead to the production of context-general midrange theories and ultimately to bodies of Mode 1 conceptual knowledge. Furthermore, we argue that if EBOCD scholars and practitioners became more active in instigating and conducting design science research and other Mode 2 studies, and these were to be focused on OCD related 'field problems' and/ or other issues of common concern or interest to managers in multiple organizations, then whether carried out by individual scholar-practitioners or in collaborative partnership with academic researchers as illustrated by Egan and Clark in Chapter 32, such studies could lead to a significant bridging or closing of the reputed 'research-practice' gap in the field of OCD.

\section{BRIDGING THE RESEARCH-PRACTICE GAP IN OCD}

In Section 1 and also in Section 3 of this two-volume book various authors have contributed chapters that discuss various forms of collaborative OCD-related research including action research, design science research, and professional partnership research. In facilitating many of these research-oriented approaches to OCD, the involved change leaders and managers acting as change agents can often be supported by internal change consultants (OD/HRD practitioners) and/or by external change consultants (OD/HRD professionals, management consultants, executive coaches). In both cases, the evidence-based OCD change agency activities involve 'consultancy' processes and 'research' processes which are similar, as depicted in the model offered by Hamlin-which he refers to as the EBOCD Conceptual Process Model: Bridging the OCD research-practice gap (see Figure 1).

Figure 1. EBOCD Conceptual Process Model: Bridging the OCD research-practice gap

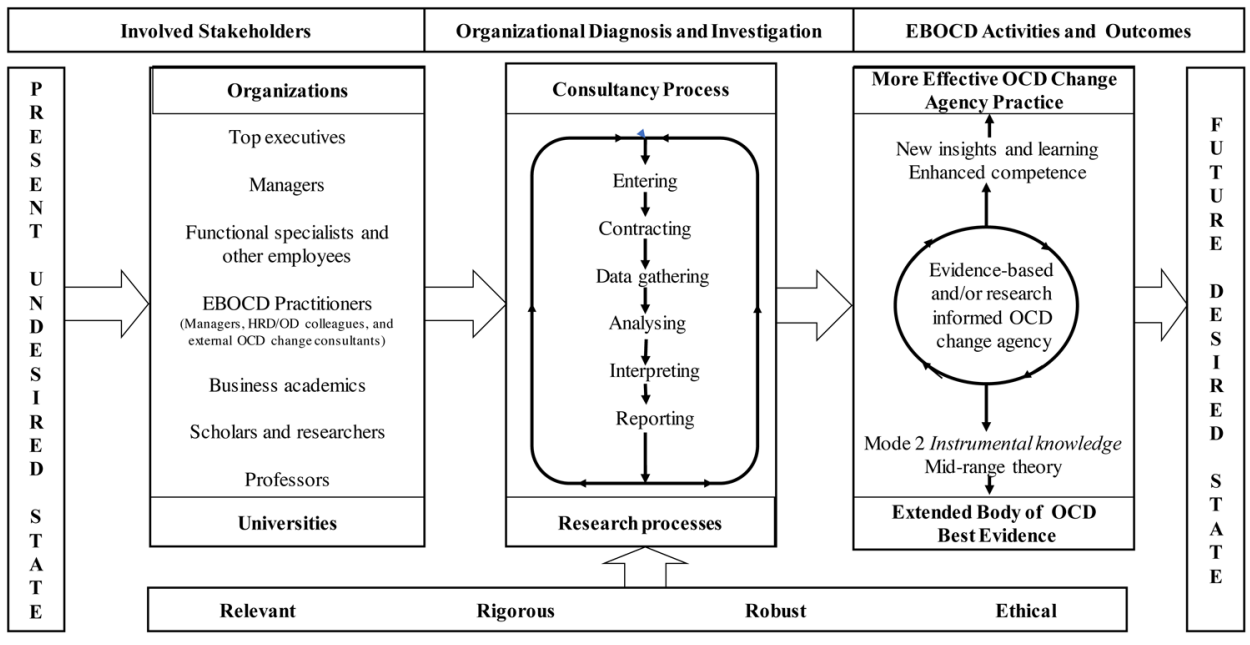

Copyright $\mathbb{C}$ R. G. Hamlin 2018 


\section{Concluding Reflections and Presentation of an EBOCD Conceptual Process Model}

Illustrating the connection between OCD-related research and consultancy processes and OCD change agency activities and outcomes, what this 'conceptual process model' attempts to show is the connection between OCD practitioners who are research-informed/evidence-based, and OCD scholars who work in collaboration with them to facilitate effective OCD initiatives. The central horizontal arrows from left to right depict the OCD change agency process of moving individuals, groups/teams and organizations from a present undesired state to a future desired state The large box to the left of centre of the model indicates the various 'stakeholders' who are collaboratively involved either directly or indirectly in facilitating the change. These include the designated OCD change agents, namely the organization's change leaders, the managers acting as change agents, and the internal and/or external change consultants who provide scholar-practitioner support. Depicted above them are the organization's employees, managers and top managers whose active support is crucial for success. Below them are the university scholars, researchers and professors who may be working in various collaborative arrangements. The large box at the centre of the model draws attention to the consultancy-based organizational diagnoses and/or research-based investigations that should take place prior to the start of and/or during the change agency process: a) to identify the real problems or root causes of the change need, b) to elicit and differentiate the 'hard facts' from the 'dangerous half-truths and total nonsense' of management and change management practice as described by Pfeffer and Sutton (2006), and c) to study the organization through academically rigorous internal research inquiries designed to gain new insights and better understanding of particular organizational phenomena or problems that are likely to have an impact on the success or failure of the OCD initiative as discussed in Chapter 2. The diagram in the middle of this box depicts the sequence of stages from contracting to reporting that is typical of the cyclical nature of the OCD consultancy process, which in many ways is similar if not identical to a conventional OCD-related internal Mode 2 research process or action research process. The long narrow box at the bottom of the model is there to indicate the importance of and need for OCD-related research to be relevant, rigorous, robust and ethical. The box to the right-hand side of the model and virtuous circle in the middle of it depict the iterative nature of evidence-based/research-informed OCD change agency which brings about the changes that lead to the 'desired future state' being achieved. The vertical arrows indicate the concomitant proximal and distal outcomes of the change agency activities that lead to: a) new learning about OCD and the enhanced competence of the internal change agents and external change consultants, and b) the outcomes of the OCD-related Mode 2 research that generates instrumental knowledge which can in some instances lead to mid-range theory development through replication logic and multiple cross-case comparative analysis, both of which can extend the extant body of OCD-related 'best evidence'.

At the turn of the $21^{\text {st }}$ century, Hamlin (2001) envisaged that as "evidence-based management becomes as firmly established and commonplace as evidence-based medicine.....more and more practitioners will use and/or engage themselves in empirical research as an 'everyday' component of their own professional practice as in the medical profession" (p. 293), and he also envisaged that " research-informed/evidencebased reflective practitioners in business are likely to become the norm rather than the exception, not least in the field of managing organizational change and development" (p. 294). The various contributions to Section 2 and Section 3 of this book offer testimony that evidence-based initiatives for OCD, or at least research-informed OCD based on critical reflection practices, is a 'reality' within a wide and culturally diverse range of countries around the globe. However, the Section 3 case histories provide little evidence about the scale of that 'reality' beyond the personal experiences described and discussed by the respective authors. Hence, as Gary McLean and Sehoon Kim suggest in Chapter 52, these 'stories' may be outlier cases in the broad field of OCD practice bearing in mind the application of evidence-based 


\section{Concluding Reflections and Presentation of an EBOCD Conceptual Process Model}

OCD is limited not only by insufficient businesspeople and OCD professionals caring about evidence, but also by the lack of relevance and utility of so much Mode 1 management-related research which leads to the widespread non-applicability of evidence in the field of management practice. McLean and Kim argue there is a need to change the paradigms associated with the publication of management and OCD related research, and this requires a shift in mind-set on the part of university administrators, journal editors and editorial boards, and authors. This is an assertion with which we fully concur.

McLean and Kim also argue that for EBOCD to occur, OCD professionals need training in research and research methods so that they possess the necessary skills to explore (and critically evaluate) existing evidence to identify where it is deficient or inappropriate for the context of an OCD problem, and to help instigate internal research to extend 'client specific evidence'. However, we suggest such skills will be put to little use unless those managers responsible for instigating OCD initiatives invite those trained OCD professionals (including HRD professional practitioners) to work with them in facilitating required change. As Hamlin (2001) argues, this is unlikely to happen "unless and until line managers overcome the five OCD 'failings' ... or until trainers and developers increase significantly their credibility in the eyes of managers" (p.294) (See also Chapter 1). This limitation appears to us as real today as it was at the start of the $21^{\text {st }}$ century, and continues to pose a major challenge for professors and academics in the OCD field, and for top managers of organizations. Echoing and further elaborating upon Hamlin's view outlined in Chapter 1 of this book, these stakeholders could make a key contribution to eliminating this limitation by, for example:

1. Management, HRD and OCD scholars who teach on Master level professional qualification programmes such as the MBA or MA/MSc in Management/Leadership ensuring that line managers who graduate from their programmes fully understand the need to embed HRD into the 'fabric' of their personal management practices and into the 'bloodstream' of the organization so that appropriate attention and effort is given to 'the role of learning in the change management process'. It is our experience that academics who teach in university schools of education and in business schools, and who are from disciplines other than HR such as education, marketing and finance, are insufficiently aware of, or tend to undervalue the critical contribution that HRD professional practitioners can make in bringing about effective and beneficial organizational change in strategic partnership with managers. It is our experience also that many HRM oriented academics who teach and train HR professionals are similarly blind to the crucial OCD-related role that HRD professional practitioners can and should play in strategic partnership with their colleague managers. Furthermore, we suspect that insufficient space is given in the curricula of management-related Master programmes to the 'soft' people issues of change management and organizational change agency. In addition, just as OCD professionals need to be trained in research and research methods so that they can effectively explore and critically evaluate the relevance and utility of extant Mode 1 and Mode 2 'best evidence' research, so too should line managers. In our view, this is of critical importance if they are to develop an in-depth understanding of what is going on deep inside their organizations, particularly the cultural factors that either enable or hinder change happening smoothly, efficiently and effectively.

2. Regarding the specific contribution of organizational leaders, senior executives and other top managers, we echo the views expressed by Hamlin in Chapter 1 who argues that they need to:

(i) become more cognizant of the 'soft' issues of management that should be considered when formulating OCD strategies, (ii) give those line managers who implement their OCD strategies 
Concluding Reflections and Presentation of an EBOCD Conceptual Process Model

sufficient time to attend to the 'soft' human side aspects of the change management processes, and (iii) increasingly recognize the value of evidence-based management, evidence-based HRD, and evidence-based coaching for bringing about effective and beneficial strategic organizational change and development.

\section{CONCLUSION}

The empirical evidence resulting from the MCCCA of the Section 3 reflective case histories demonstrates that EBOCD is a practical 'reality' within a wide range of private, public and third (non-profit) sector organizations in a culturally diverse range of countries around the globe, and this is supported by the additional evidence of EBOCD that has emerged from the practical experiences of our Section 2 chapter authors. Thus, we suggest EBP approaches to OCD are likely to exist far more extensively than suggested by Mclean and Kim in Chapter 52. The fact that most of our Section 2 and Section 3 chapter authors were already known to us through our various HRD and Coaching and Mentoring networks and have contributed their respective chapters by invitation and not through a general call for contributions, suggests the examples of evidence-based OCD initiatives presented in this book are drawn almost exclusively from two 'communities of change agency practice' within the whole field of OCD and change management consultancy. We believe that, if, in future, a similar call could be disseminated through the various networks of OCD practitioners affiliated to the Academy of Management in the USA and the British Academy of Management in the UK, and to other relevant OCD-related organizations like the OD Network, the OD Institute, and the Society of Industrial and Organizational Psychology (SIOP), then most likely much more evidence of the 'reality' of EBOCD would emerge.

It is interesting to note that the findings of our multiple cross-case comparison of the Section 3 reflective case histories lend strong support to the 10 common 'insights' and 'lessons' (CILs) about 'research informed' and 'evidence-based' OCD practice as identified almost 18 or so years ago by Hamlin (2001), and the findings reported in this chapter have also revealed the emergence of 10 'new' CILs. We hope these common 'insights' and 'lessons' will provoke thought and provide useful guidance to readers who will soon be engaged in instigating and/or designing and facilitating future evidence-based initiatives for OCD.

By presenting the 'EBOCD Conceptual Process Model' created by Hamlin to illustrate the connections between 'OCD-related consultancy and research processes' and 'OCD change agency activities and outcomes', the chapter provides a step forward in bridging the long-existing and reputed scholarpractitioner gap in HRD and management, and it also suggests pathways for generating OCD related 'best evidence' through various forms of Mode 2 research.

\section{REFERENCES}

Antonakis, J. (2017). Editorial: The future of the Leadership Quarterly. The Leadership Quarterly, 28(1), 1-4. doi:10.1016/j.leaqua.2017.01.005

Bettis, R. A., Ethiraj, S., Gambardella, A., Helfat, C., \& Mitchell, W. (2016). Creating repeatable cumulative knowledge in strategic management: A call for a broad and deep conversation among authors, referees, and editors. Strategic Management Journal, 37(2), 257-261. doi:10.1002mj.2477 
Eisenhardt, K. M. (1989). Building theories from case study research. Academy of Management Review, 14(4), 532-550. doi:10.5465/amr.1989.4308385

Flick, U. (2014). An introduction to qualitative research (5th ed.). London: Sage.

Hamlin, R. G. (2001). Towards research-based organizational change and development. In B. Hamlin, J. Keep, \& K. Ash (Eds.), Organizational change and development: A reflective guide for managers, trainers and developers (pp. 283-296). Harlow, UK: FT Prentice Hall.

Hamlin, R. G. (2016). Evidence-based organizational change and development: Role of professional partnership and replication research. In C. Hughes \& M. W. Gosney (Eds.), Bridging the scholar-practitioner gap in human resources development (pp. 120-142). Hershey, PA: IGI Global.

Hamlin, R. G., Keep, J., \& Ash, K. (2001). Organizational change and development: A reflective guide for managers, trainers and developers. Harlow, UK: FT Prentice Hall.

Hughes, C., \& Gosney, M. W. (2016). Bridging the scholar-practitioner gap in human resources development. Hershey, PA: IGI Global. doi:10.4018/978-1-4666-9998-4

Pfeffer, J., \& Sutton, R. I. (2006). Hard facts, dangerous half-truths \& total nonsense: Profiting from evidence-based management. Boston: Harvard Business School Press.

Tsang, E. K. K., \& Kwan, K.-M. (1999). Replication and theory development in organizational science: A critical realist perspective. Academy of Management Review, 24(4), 759-780. doi:10.5465/ amr.1999.2553252 